\title{
Reflexiones, sobre el Siglo de Oro, desde un tiempo de hierro ${ }^{1}$
}

\author{
MIGUEL FERNÁNDEZ-PACHECO, MADRID - ESPAÑA
}

Fecha de recepción: julio de 2014

Fecha de aceptación: julio de 2014

A Diego Velázquez retratar a la infanta Margarita, hijapredilecta del rey Felipe IV, rodeada de sus damas y bufones se le antoja, hoy más que nunca, tarea ardua. Todos los personajes del cuadro están ya prácticamente acabados de pintar, pero la Infanta hace tiempo que no viene al estudio. Parece que se aburre posando. Murmuran que anoche se atrevió a confesárselo a su padre después de la cena.

¡Y Su Católica Majestad ha dicho que le cuenten cuentos! Protestan las meninas, los guardadamas, los enanos, hasta el propio pintor de cámara se queja.

Sin embargo, cuando aparece radiante la Infanta, la situación se complica y los presentes rivalizan en referir historias de amor, único género de relato que la niña está dispuesta a escuchar.

Así, desfilarán ante el lector leyendas que pudieran ser reales y sucesos verdaderos que parecen inventados. Narraciones sorprendentes, que van desde turbias intrigas cortesanas hasta tiernas aventuras entre sarracenos, donde no falta un enano devoto, una princesa dispuesta a todo por amor, un príncipe jabalí, un pirata apasionado, un novio fantasmal, un perro encantado, amén de otros fabulosos prodigios...

1 Publicado originalmente en Institución Libre de Enseñanza: Boletín, II a Época, № 49-50. Madrid, mayo 2003, p.87-96. Reproducido aquí bajo autorización escrita de su autor. 
Así reza la contracubierta del libro Siete historias para la infanta Margarita que se editó en Siruela, en octubre del 2001, tras no pocos avatares. El último de sus cuentos Verdadera historia del perro Salomón fue publicado por S.M., un año antes, en forma de álbum, ilustrado por Javier Serrano y recibió, aparte del Premio Internacional de Ilustración de la Fundación Santa María, un Nacional de Ilustración y otro de Literatura Infantil y Juvenil, ambos otorgados por el Ministerio de Cultura. Es curioso que apenas se hiciera notar en las librerías -los vendedores de libros de este país aseguran que los "álbumes" no se venden $y$, por tanto, ni se molestan en distribuirlos- por eso casi nadie lo conoce.

Pero el origen de todo comenzó muchos años atrás, cuando el Museo del Prado era gratuito para los españoles -o tempora, o mores-y yo vivía muy cerca deél. Durante meses, iba casi todos los días, diez minutos, a mirar Las Meninas, en la maravillosa instalación que tenía, no en la que tiene ahora. Resultó un experimento de lo más interesante. Cada vez veía un cuadro distinto, como si se renovara por las noches. Comprendí así que las obras de arte pueden resistir muchas miradas sin llegar a cansar, igual que una buena novela tiene muchas lecturas. Al fin acabé pensando que el cuadro hablaba y decidí escribir sobre lo que sus personajes me decían. Pero como tantas cosas difíciles de las que suelo plantearme a la hora de escribir, el tema hubo de madurar durante años.

Primero me salió una obrita de teatro, con un solo escenario, el cuadro. Por supuesto nadie la representó. Incluso algunos editores se negaron a publicarla aduciendo que las obras de teatro tampoco se venden en estos pagos. Hay que ver en qué lugar tan raro vivimos.

Decidí pues transformarla en novelilla juvenil, o más bien en colección de cuentos. Como drama, por razones de tiempo escénico, solo tenía tres: Leyenda delenano enamorado, basado en otro cuadro de Velázquez, el delbufón llamado El primo, Crónica de Alcaucín y Nicolasilla versión libre y notoriamente acortada, de unfablieau medieval francés Aucassin y Nicolette; yla ya citada Verdadera historia del perro Salomón, que naturalmente relata la asombrosa vida del perro que aparece en la pintura. Luego, al novelarla, le añadí: El príncipe jabatón, versión personal del cuento de hadas de la escandalosa baronesa D’Aulnoy; la Fidedigna relación de los amores de Doña Marcela de Ulloa con un bucanero, en mi modesta opinión la mejor historia de las siete que encierra la colección; Amor más allá de la muerte que trata de un novio fantasma, y no desmerece de la anterior, y la Historia del siervo de Dios Juan Arconado, algo irreverente, a mi juicio, aunque la Comisión Católica de la Infancia no lo tuviera en cuenta cuando lo incluyó en su lista de libros recomendados. La presentéasía varias editoriales que no la consideraron y a varios premios que no ganó. Hasta que una editora sensible, Ofelia Grande, actual directora de Siruela, decidió publicarla.

Cuando se publica un libro siempre se queda uno un poco en blanco, siempre está bastante perplejo antelo que debería decir-o no decir-, deél. Luego, en 
alguna biblioteca-el que esto escribe no suele ir a colegios-algún lector le hace preguntas que le ayudan a reflexionar sobre lo que realmente hizo o pretendió hacer. Transcribiré aquí unas cuantas:

-¿Por qué escribir sobre el llamado "siglo de oro"?

Cuando me lo preguntaron por primera vez, dudé sobre lo que debería contestar, pero al fin me salió:

-Posiblemente porque no haya en la historia de España una época más hipócrita que esa... salvo la nuestra, claro.

Cuando se dice algo tan discutible, no hay más remedio que empezar a explicarlo. Así que tampoco se puede evitar decir cosas del estilo de lo que sigue:

Es bien evidente que dentro de la decadencia del gran imperio españolque se inicia probablemente con Felipe II y alcanza acaso su cenit, con Isabel II, tatarabuela de nuestro actual soberano-, la época de Don Felipe IV, "el rey pasmado", relumbra con auténticaluz propia. En ella, la oscuridad delas guerras con los flamencos, las sombrías megalomanías del favorito Olivares, el turbio desbarajuste colonial, la opacidad de la bancarrota generalizada y la más negra desmoralización, tanto de la corte como del pueblo llano, conviven con la brillantez de los dramas de Lope o el esplendor de los autos de Calderón, con la clara agudeza de Quevedo o la luminosa gracia de Góngora, por no decir con el deslumbrante Quijote de Cervantes... ¿Es posible mayor hipocresía? Y lo digo en el sentido de ¿es posible mayor disociación entre lo que se dice, lo que se hace y lo que se piensa?

Pues bien, existe una obra de arte que sintetiza admirablemente la falsedad barroca y lo más sorprendente de ella es que está plasmada con una intención de autenticidad casi absoluta, es decir, con un verismo sorprendente. Se trata de Las Meninas de don Diego Velázquez de Silva. Es difícil encontrar un cuadro más artificioso y al mismo tiempo más preciosamente realista que ese. Se han vertido ríos de tinta en torno suyo, tratando de esclarecer las muchas ambigüedades y misterios que encierra. Solo esbozaré unos cuantos detalles para dar una ligera idea de su rebuscada singularidad y de sus muchas "rarezas".

El género de retrato de familia, al que puede pertenecer Las Meninas -es decir, el retrato de una o varias personas cercanas al pintor, en el estudio de ésteno es nada corriente en nuestra pintura, ni siquiera en la del propio Velázquez, que toma la idea de la escuela holandesa, que probablemente conocería y que es pródiga en ellos. Sin embargo solo recuerdo otro en el que aparezca también el pintor y es el llamado: El arte de la pintura, de Johannes Vermeer de Delft; donde aun se va más lejos, porque ahí el pintor aparece de espaldas y, dada la posición en que está en el cuadro, no puede verse en ninguna parte.

En Las Meninas Don Diego mira al público. Todos los personajes de un modo u otro lo hacen ¿convirtiéndose en espectadores del que mira, tal vez? y, por otra parte, ¿qué está mirando realmente el pintor? ¿Se trata de un espejo donde se ve toda la escena? ¿Un espejo tan enorme? Parece poco creíble en esas 
fechas. Además, si hubiera copiado su imagen de un espejo, no veríamos el pincel del pintor en su mano derecha. Si el artista no pinta lo que vemos ¿qué está pintando entonces? ¿Son los reyes, que ocupan el lugar del espectador, como algunos sensatamente han dicho? Todo es posible en este extraño cuadro y es evidente que esa escena, que parece tan normal, no lo es en absoluto.

Queda entonces solo la inmensa belleza de esos grises plateados, la soltura asombrosa de esa pincelada, más sugeridora que definidora, el sólido equilibro dela composición y en fin, lo indefinible, lo misterioso, expresado en esas caras, esas manos, esas actitudes, esaluz, ese aire, que cientos delibros no han acabado aún de precisar, de definir, de acotar...

Conque por acabar con el cuadro inacabable, citaré un precioso poema modernista de Don Manuel Machado, que también tiene algo que ver con su plateada esplendidez.

\section{LA INFANTA MARGARITA}

Como una flor clorótica el semblante, que hábil pincel tiñó de leche y fresa, emerge del pomposo guardainfante, entre sus galas cortesanas presa.

La mano -ámbar de ensueño- entre los tules

de la falda desmáyase y sostiene el pañuelo riquísimo, que viene de los ojos atónitos y azules.

Italia, Flandes, Portugal..., poniente sol de la gloria el último destello en sus mejillas infantiles posa...

Y corona no más su augusta frente la dorada ceniza del cabello, que apenas prende el leve lazo rosa.

¿Y cómo es posible que tanta hermosura se produjera en el pavoroso vórtice de tanta crisis? ¿Acaso por eso mismo?

Pero vayamos a otro punto.

Una vez llegados hasta aquí, se me acostumbra a hacer otra pregunta que suele poner en relación los contrasentidos barrocos y nuestros propios contrasentidos:

- ¿Por qué considera a nuestra época tan hipócrita? 
Bueno, lo cierto es que no la considero solo tan hipócrita, sino la más hipócrita de todas las épocas. Incluso diría que la hipocresía es uno de sus rasgos menos graves. Vivimos el momento más salvajemente destructivo de la historia de la humanidad.

Y como comprendo que afirmación tan categórica también merece una explicación, intentaré aclararla, utilizando solo tres argumentos relacionados con el tiempo, por no alargar innecesariamente la respuesta.

Comenzarécitandoa Ernst Jünger, quien en El libro del relojde arena dice así:

\begin{abstract}
Que el día y la noche tengan cada uno doce horas es una ficción relativamente joven. Palabras como amanecer, crepúsculo, tarde y mañana son designaciones para espacios de tiempo fluidos, que se confunden entre sí. Nuestros antepasados no sufrieron a causa de esta inexactitud, antes al contrario, debemos colegir que llegaban "demasiado tarde" con mucha menos frecuencia que nosotros, debido a que su presencia determinaba el trabajo, mientras que ahora el horario de trabajo automatizado impone nuestra presencia.

El cazador, el pescador, el pastor vivían fuera del tiempo mensurable y abstracto. Su tiempo era concreto, ya que se adaptaba a su actividad y ésta determinaba la hora y su valor, mientras que la parte principal de nuestros negocios gira en torno a un horario, se rige por el reloj. Esta diferencia es fundamental. Una hora de clase, una sesión parlamentaria, una hora de trabajo en una empresa mecanizada, se pueden desplazar, empujar como bolas de ábaco o sustituir entre sí.
\end{abstract}

Pues bien, nuestra época ha introducido, entre ese ritmo -sagrado para el zen-, de la naturaleza y nosotros, algo más contundente que un reloj de cuarzo. Con una lógica algo oscura, las "autoridades" de algunos lugares de nuestro planeta introducen una cuña ¡de una hora! al principio de la primavera y el otoño de cada año, que durante meses nos distancia dos de la solar, produciéndonos molestias, en ciertos casos, parecidas a las de los vuelos transoceánicos. Mencionan, para semejante trastorno, vagas razones económicas que nadie, en el fondo, entiende, aunque las acate y trate de adaptarse a ellas.

En cambio, al hablar de los ordenadores, que han vuelto inabarcablemente rico a Bill Gates, no suelen mencionarse razones económicas, sino directamente funcionales. Ciertamente, el ordenador, que ha generado millones de parados en el llamado "primer mundo", es una herramienta fabulosa. ¿Pero en qué sentido? Naturalmente en el del tiempo. Ahorra tiempo en el trabajo: Ahora bien ¿estamos seguros de que el ahorro de tiempo en el trabajo es de algún modo un bien para el hombre? Personalmente, ni siquiera estoy seguro de que sea un bien para Bill Gates. Se me antoja un contrasentido más, de los muchos que caracterizan nuestro mundo.

Mencionaréotro ejemplo aún más pernicioso quelos anteriores, pues cuesta más vidas que algunas guerras. Se trata del automóvil. Cada fin de semana, las prisas de los automovilistas domingueros arrojan a nuestro país entre $50 \mathrm{y}$ 70 bajas, lo que al cabo del año supone en torno a 3.000, sin contar hospitali- 
zados varios, algunos de por vida. Si sumamos los muertos en carretera que se producen en un año en Europa la cifra ronda las 50.000 personas. Mueren por ir deprisa. Cabría preguntarse ¿a dónde? y también ¿para qué? En principio, quizás para que el petróleo siga subiendo y acaso también para que el delirante sin sentido de nuestro mundo se espese aún más. Un sin sentido donde se están sobrepasando todos los límites imaginables en cuanto a vesania, una época donde, por televisión, en cuidados reportajes, podemos apreciar cómo se deforesta el planeta, o cómo se bombardea con saña a viejos, mujeres y niños en algún país, preferentemente musulmán, o cómo se prostituye a menoreso cómo se trafica con sus órganos o con drogas... ¿ son suficientes ejemplos?

Con todo, lo más triste de esta época, atrozmente sanguinaria ybrutalmente injusta, es que no produce apenas belleza.

La incuria de Habsburgos y Borbones, aquella soberbia absolutista, aquella ruina espectacular, cortejada de hambrunas y pestes, aquella imbecilidad congénita, dejó España llena de arquitectura, de escultura, de pintura, de dramas y comedias, de pasos y entremeses, de novelas y cuentos. ¿Quénos dejará nuestro tiempo? ¿Quépervivirá de los fastos dela Coca-Cola o el Burger King? ¿Adónde irán a parar las apoteosis del Real Madrid o de Operación Triunfo? Y estoy hablando de fenómenos realmente populares y, en cierto sentido, democráticos; porque el llamado arte contemporáneo es la cosa más tristemente académica que se pueda imaginar.

Mircea Eliade lo dice así en Aspectos del mito:

La incomprensión agresiva del público, de los críticos y de las representaciones oficiales del arte hacia un Rimbaud o un Van Gogh, las consecuencias desastrosas que tuvo, sobre todo para los coleccionistas y los museos, la indiferencia hacia los movimientos innovadores, desde el impresionismo al cubismo y al surrealismo, han constituido duras lecciones tanto para los críticos y el público como para los marchantes de cuadros, las administraciones de los museos y los coleccionistas. Hoy, su único miedo es no ser lo suficientemente avanzados, el no adivinar a tiempo el genio en una obra a primera vista ininteligible. Jamás quizás en la historia, el artista ha tenido tanta certeza como hoy que, cuanto más audaz, iconoclasta, absurdo e inaccesible sea, tanto más se reconocerá su valía, se le mimará, se le idolatrará. En algunos países se ha llegado a un academicismo de "vanguardia"; hasta tal punto que toda experiencia artística que no tenga en cuenta este nuevo conformismo, corre el riesgo de ser sofocada o de pasar inadvertida.

Sin comentarios.

Con semejantes opiniones se comprenderá que no esté interesado en escribir sobre nuestro tiempo. Así contesto a otra de las preguntas que se me suelen formular. A saber:

-¿Por qué no escribe historias de hoy?

Para empezar, considero que el mundo está lleno de excelentes escritores -cronistas, que cuentan maravillosamente todo lo que pasa. Yo me he hecho, por eso, especialista en contar, justamente, lo que no pasa. $\mathrm{O}$, dicho de 
otro modo: el mejor desprecio que se le puede hacer a nuestro tiempo es no apreciarlo.

Por otra parte, tal decisión no ha sido el resultado de ningún manifiesto apriorístico, ni ninguna declaración de principios. Ha intervenidola experiencia y mis publicaciones de diez años a esta parte, que cumplen con la premisa de no narrar nada de aquí, nada de ahora, se basan en la práctica de otros quince años, anteriores.

Ciertamente, me encuentro más cómodo dentro de un género que podría calificarse de "histórico". De hecho, cuando en las estanterías de las grandes librerías colocan mis libros en ese apartado, cosa que a veces ha ocurrido, me encuentro casi menos incómodo que siendo autor de algo como lo que llaman "literatura infantil". Pero igual que mi intención básica no es propiamente escribir para niños, tampoco es la de reflejar fielmente una época. Utilizo el tiempo histórico como marco para la actuación de unos personajes. Personajes de los que me preocupa más la ética que la peripecia, aunque cuide extraordinariamente lo que ocurre.

Debido a ello creo que no me puedo considerar un narrador como Alejandro Dumas -y no solo porque él era un gran novelista y yo, a duras penas, consigo ser un novelista de este tiempo-, sino porque mi intención no es recrear una época concreta sino hacer más creíbles unas actitudes difíciles de aceptar en la nuestra.

- ¿Entonces le encantará Michel Ende o Tolkien, que sitúan sus acciones en tiempos y lugares inexistentes?- se me podría preguntar también.

Y de hecho se me ha preguntado alguna vez. Lo cierto es que no. Tampoco me sentiría cómodo con la fantasía por la fantasía, entre reglas del juego que se van inventando según va conviniendo. No conozco nada más aburrido para un escritor. El mecanismo es como el de la novela policíaca, en la que el autor lo sabe todo de antemano y va jugando al ratón y al gato con el lector, revelándole lo que le conviene cómo y cuándo le conviene. Comprendo que para el que lee, esa dinámica pueda resultar apasionante, pero para el que escribe, al menos para el que escribe como yo, no hay nada más tedioso.

Personalmente, me entretiene mucho más que mis personajes me sorprendan, metiéndose en situaciones imprevistas; pero para eso, el tiempo histórico en el que se mueven ha de ser muy real, con las auténticas reglas del juego que regían en otras épocas. Eso, lógicamente, me obliga a trabajar mucho y a aprender muchísima historia, pero el resultado es, al final, apasionante. Como un reto que me fascina.

Por otra parte, lo mejor de esa diversión es el comportamiento de esos personajes, normalmente regido por anhelos, y aún pasiones, éticas. Inmersos en deudas de honor, compromisos, palabras empeñadas... En fin, anhelos y pasiones imposibles en nuestros días. Para que se entienda mejor lo que pre- 
tendo voy a referirme a ciertos relatos, de todos conocidos, como por ejemplo el Robinson de Daniel Defoe.

Naturalmente, el protagonista, en su isla desierta, está marcado por su tiempo, hallegado a ella en determinado barco, posee una escopeta con determinado mecanismo y unos conocimientos determinados, que por supuesto respeta y que son estrictamente históricos, tiene además una relación con Viernes, dentro de las coordenadas de comportamiento típicas de su tiempo. Pero todas las características del relato podrían cambiar cincuenta o cien años arriba o abajo sin afectar gran cosa el comportamiento de Robinson. De hecho las Robinsonadas posteriores cambiaron casi todos los detalles temporales, pero respetando el espíritu de la primera.

Igual de claro, por otras razones, es el caso de Los viajes de Gulliver que podrían estar fechadas antes o después, ya que su destino narrativo pretende ser atemporal.

Con respecto a esta obra me parece curioso reproducir lo que dice Alberto Manguel en su libro Una historia de la lectura.

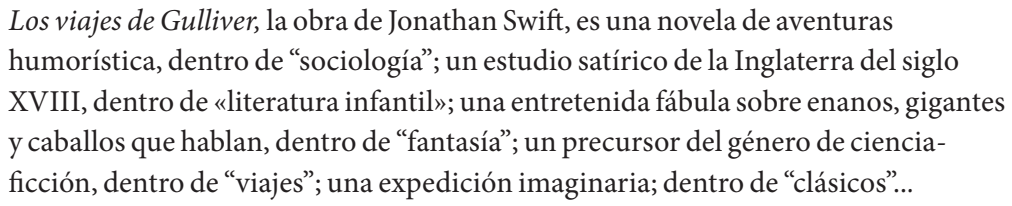

Con esto acabaría proclamando que me encantaría haber escrito, y continuar escribiendo, obras perfectamente atemporales, que pudieran leerse con placer en otros momentos de un futuro, si posible, algo más noble que el que se ve venir y, por supuesto, obras altamente inclasificables, que mis queridos amigos bibliotecarios sufrieran de verdad para archivar, pues ello sería señal de que son obras vivas, no sujetas a ninguna moda ni a ninguna convención.

También me gustaría que se me tuviera por un escritor moral, en el sentido más profundo y serio de la palabra; edificante como lo son Molière o Shakespeare -salvando los naturales abismos que nos separan- lejos por tanto de todo lo que se considera políticamente correcto y que tiene más que ver con la hipocresía, propia de nuestro mundo, que con ningún código o regla de comportamiento.

Códigos y reglas de las que estamos más necesitados que nunca, por eso las despreciamos tan olímpicamente, en nombre de una libertad imposible sin ellas.

Solo hay algo que falta en nuestro mundo más que un auténtico sistema, y son las verdaderas ideas, a las que escarnecemos y olvidamos aún más que a las normas... ¿Y cómo recuperar todo eso? pueden decir los pocos que quieran entenderme... Empecemos por recuperar el tiempo. Pero ojo, no el de la tele, el ordenador o el automóvil... Otro tiempo. El tiempo de la memoria. 